\title{
Modeling and Simulation of Doubly Fed Induction Wind Generator Based on Matlab / Simulink
}

\author{
Yun Sha \\ North China Electric Power University, Changping District, Beijing \\ 1124756041@qq.com
}

Keywords: Wind turbine; DFIG; Vector control strategy; Active and reactive power control

\begin{abstract}
Targeting the doubly-fed wind power system, this paper establishes the overall mathematical model composed of wind turbine, drive system, double-fed induction generator, stator flux orientation vector control tactics, maximum power point tracking tactics. By applying the simulink in the matlab software, and based on the mathematical model mentioned above, the paper also sets up a double -fed wind power system simulation model, and taking two step-up wind speeds as examples, simulation studies are made on the dynamic characteristics of the model with the grid connected. The simulation studies show that the model realizes the maximum power point tracking and decoupling control of power, and the double-fed wind power system has satisfactory dynamic characteristics, thus proving that the model established is correct and valid.
\end{abstract}

\section{Introduction}

During the past two decades, there has been tremendous growth in many aspects of wind power generation and related technologies. The capabilities of wind turbine generators (WTGs) have improved significantly in conjunction with the process made in power electronic industries, both in terms of the costs and capabilities; thus, it is possible to build modern wind turbines to meet modern grid requirement at affordable costs.

Wind turbine installations have continued to multiply, and the penetration level of wind generation on the grid has steadily increased. Similarly, challenges in operating a power system with high penetration levels of wind power within the next few years. In anticipation of these challenges, the wind industry and utility industry have been moving forward developing dynamic models for WTG and wind power plant (WPP). Each group of WTGs constitutes a significant portion of the output power of the WPP[1-5].

The development of a dynamic model of a WTG is the first major step toward representing a WPP, wherein the WTG is represented correctly in the power system instead of a negative load. The next step is to validate the WTG dynamic model to ensure it can be represented as accurately as possible to the actual turbine.

\section{Mathematical Model}

Mathematical Model of Wind Turbine. The mechanical energy acquired from wind by turbines is a complex function, whose variables include wind speed, pitch angle of blade and mechanical rotating speed. The function can be described by algebraic equations as follows,

$$
P_{m}=\frac{1}{2} \rho V_{w} r C_{p}(\lambda, \theta)
$$

In the formula, ${ }^{P_{m}}$ is mechanical energy acquired from wind $(\mathrm{W}) ; \rho_{\text {is air density }(\mathrm{kg} / \mathrm{m} 3) ; r}$ is radius of turbine blade $(\mathrm{m}) ;{ }^{v_{w}}$ is wind $\operatorname{speed}(\mathrm{m} / \mathrm{s}) ;{ }^{C}$ is wind power factor; $\lambda$ (blade speed ratio) is the ratio of blade tip speed and wind speed,which is,

$$
\lambda=\frac{\omega_{t} r}{v_{w}}
$$


In the formula, $w_{t}$ is mechanical rotating speed $(\mathrm{rad} / \mathrm{s})$.

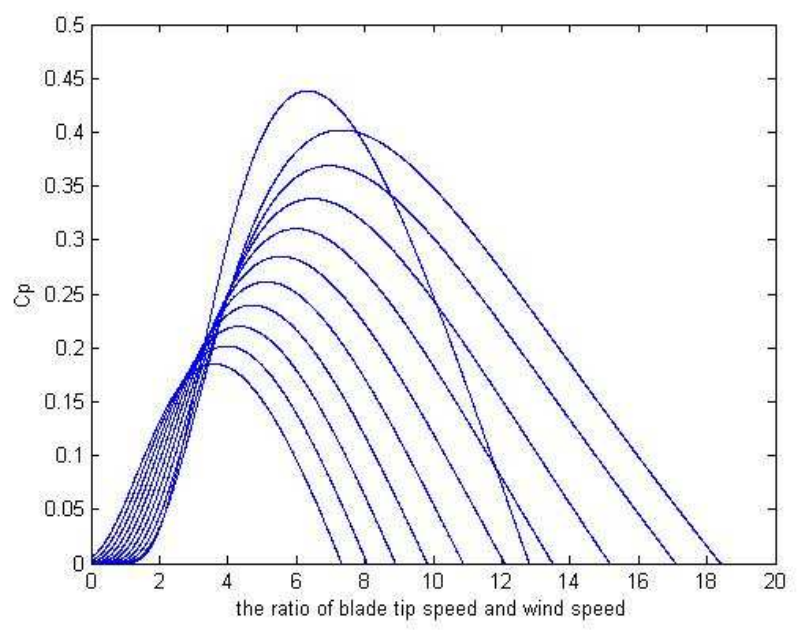

Figure 1. The variation curve of power factor with blade speed ratio

The relationship between wind power factor and ratio of blade tip speed and wind speed is shown in Fig. 1. For a given blade pitch angle, the difference of wind power energy factor to the different blade tip ratio is large, and only one optimum tip speed ratio can maximize the wind power factor. In the case of constant wind speed, to maintain the best tip speed ratio, the wind turbine mechanical speed changes referring to the wind speed. Only maintaining the best tip speed ratio can turbine captures the maximum wind energy.

Mathematical Model of Mechanical Transmission. The mechanical transmission between the hub and the rotor of the generator is described by the practical model of a mass when the hardness and damping coefficients are ignored. The formula is as follows[6]:

$$
T_{\text {gen }}-T_{\text {wind }}=J_{d} \frac{d \Omega_{e}}{d t}
$$

In the formula, $T_{\text {wind }}$ is equivalent torque of hub, $T_{g e n}$ is rotor torque, $J_{d}$ is equivalent moment of inertia, $\Omega_{e}$ is mechanical rotating speed of rotor.

Mathematical Model of Doubly Fed Induction Generator. In the establishment of mathematical model, the stator current to flow out is the positive and the rotor current to flow in is the positive.

The stator winding voltage equation is:

$$
\begin{aligned}
& u_{d 1}=P \psi_{d 1}-\omega_{1} \psi_{q 1}-R_{1} i_{d 1} \\
& u_{q 1}=P \psi_{q 1}-\omega_{1} \psi_{d 1}-R_{1} i_{q 1}
\end{aligned}
$$

The rotor winding voltage equation is:

$$
\begin{aligned}
& u_{d 2}=P \psi_{d 2}-\omega_{s} \psi_{q 2}+R_{2} i_{d 2} \\
& u_{q 2}=P \psi_{q 2}-\omega_{s} \psi_{d 2}+R_{2} i_{q 2}
\end{aligned}
$$

In the formula, $u_{d 1} u_{q 1} u_{d 2}$ and $u_{q 2}$ are respectively the $d 、 q$ components of the stator and rotor's voltage. $i_{d 1} i_{q 1} i_{d 2}$ and $i_{q 2}$ are respectively the $d, q$ components of the stator and rotor's current. $\omega_{s}=\omega_{1}-\omega_{r}$ is the angular velocity of $d q$ coordinate system relative to the rotor's one.

The flux linkage equation is: 


$$
\left\{\begin{array}{l}
\psi_{d 1}=-L_{1} i_{d 1}+L_{m} i_{d 2} \\
\psi_{q 1}=-L_{1} i_{q 1}+L_{m} i_{q 2} \\
\psi_{d 2}=-L_{m} i_{d 1}+L_{s} i_{d 2} \\
\psi_{q 2}=-L_{m} i_{q 1}+L_{2} i_{q 2}
\end{array}\right.
$$

In the formula, $\psi_{d 1} \psi_{q 1} \psi_{d 2} \psi_{q 2}$ are respectively the $d q$ component of the stator and rotor's flux; $L_{1}$ is the equivalent inductance between two - phase stator windings in the $d q$ coordinate system; $L_{m}$ is the equivalent inductance between stator and rotor windings coaxially in th $d q$ coordinate system; $L_{2}$ is the equivalent inductance between two - phase stator windings in the $d q$ coordinate system;

Therefore, The relationship between current and voltage is: $P$ is differential symbol.

$$
\left[\begin{array}{l}
u_{d 1} \\
u_{q 1} \\
u_{d 2} \\
u_{q 2}
\end{array}\right]=\left[\begin{array}{cccc}
-R_{1}-L_{1} P & \omega_{1} L_{1} & L_{m} P & -\omega_{1} L_{m} \\
-\omega_{1} L_{1} & -R_{1}-L_{1} P & \omega_{1} L_{m} & L_{m} P \\
-L_{m} P & \omega_{s} L_{m} & -R_{2}-L_{2} P & -\omega_{s} L_{2} \\
-\omega_{s} L_{m} & -L_{m} P & \omega_{s} L_{2} & R_{2}+L_{2} P
\end{array}\right]\left[\begin{array}{l}
i_{d 1} \\
i_{q 1} \\
i_{d 2} \\
i_{q 2}
\end{array}\right]
$$

The electromagnetic torque equation is:

$$
T_{e m}=\frac{3}{2} N_{p} L_{m}\left(i_{q 1} i_{d 2}-i_{d 1} i_{q 2}\right)
$$

The power equation is:

$$
\left\{\begin{array}{l}
P_{1}=\frac{3}{2}\left(u_{d 1} i_{d 1}+u_{q 1} i_{q 1}\right) \\
Q_{1}=\frac{3}{2}\left(u_{q 1} i_{d 1}-u_{d 1} i_{q 1}\right) \\
P_{2}=\frac{3}{2}\left(u_{d 2} i_{d 2}+u_{q 2} i_{q 2}\right) \\
Q_{2}=\frac{3}{2}\left(u_{q 2} i_{d 2}-u_{d 2} i_{q 2}\right)
\end{array}\right.
$$

Where, $P_{1}$ and $Q_{1}$ are respectively active power and reactive power from stator to power grid; $P_{2}$ and $Q_{2}$ respectively active power and reactive power from power grid to rotor.

Vector Control Strategy. Vector control theory is proposed by the German F.B laschke in 1971, the application of vector control technology makes the AC speed control really get the same excellent performance as the DC speed control. After more than 20 years of industrial practice test and improvement, it has now reached the mature stage.In this theory, the AC motor stator's current is decomposed into excitation and torque variable according the theory of motor unity and coordinate transformation, After the decomposition of the stator current excitation components and torque components, they no longer have a coupling relationship and they can be controlled respectively. You can achieve the AC motor flux and torque decoupling control, so that the AC motor can be comparable to the control performance of DC The motor[7-8].

DFIG stator windings are directly connected to the infinite power grid, the stator voltage amplitude and frequency are constant approximately.In this paper, the vector control of stator flux orientation (SFO) is adopted. When the stator flux is oriented, it is assumed that the stator flux $d$ vector coincides with the axial direction. 


$$
\left\{\begin{array}{l}
\psi_{d 1}=\psi_{1} \\
\psi_{q 1}=0
\end{array}\right.
$$

When the stator resistance is ignored:

$$
\left\{\begin{array}{l}
u_{d 2}=p i_{d 2}\left(L_{2}-\frac{L_{m}{ }^{2}}{L_{1}}\right)-\omega_{s} i_{q 2}\left(L_{2}-\frac{L_{m}{ }^{2}}{L_{1}}\right)+R_{2} i_{d 2} \\
u_{q 2}=p i_{q 2}\left(L_{2}-\frac{L_{m}{ }^{2}}{L_{1}}\right)+\omega_{s}\left[\frac{L_{m}}{L_{1} \omega_{1}} u_{1}+i_{d 2}\left(L_{2}-\frac{L_{m}{ }^{2}}{L_{1}}\right)\right]+R_{2} i_{q 2}
\end{array}\right.
$$

Considering that the rotor voltage and current are not fully decoupled, we assume:

$$
\left\{\begin{array}{l}
u_{d 2}{ }^{\prime}=p i_{d 2}\left(L_{2}-\frac{L_{m}{ }^{2}}{L_{1}}\right)+R_{2} i_{d 2} \\
u_{q 2}{ }^{\prime}=p i_{q 2}\left(L_{2}-\frac{L_{m}{ }^{2}}{L_{1}}\right)+R_{2} i_{q 2} \\
\Delta u_{d 2}=-\omega_{s} i_{q 2}\left(L_{2}-\frac{L_{m}{ }^{2}}{L_{1}}\right) \\
\Delta u_{q 2}=\omega_{s}\left[\frac{L_{m}}{L_{1} \omega_{1}} u_{1}+i_{d 2}\left(L_{2}-\frac{L_{m}{ }^{2}}{L_{1}}\right)\right]
\end{array}\right.
$$

Where, $u_{d 2}{ }^{\prime}$ and $u_{q 2}$ ' are the decoupling section; $\Delta u_{d 2}$ and $\Delta u_{q 2}$ are the compensation section. The stator side power equation is:

$$
\left\{\begin{array}{l}
P_{1}=\frac{3}{2} \frac{L_{m} u_{1}}{L_{1}} i_{q 2} \\
Q_{1}=\frac{3}{2}\left(\frac{L_{m} u_{1}}{L_{1}} i_{q 2}-\frac{u_{1}^{2}}{L_{1} \omega_{1}}\right)
\end{array}\right.
$$

It can be seen from the above formula, controlling the rotor current axis component can control the stator winding active output and controlling the rotor current axis component can control the stator winding reactive output. Through the vector control technology, we can achieve active and negative decoupling control.

Active and Reactive Power Control. The reference value for torque or active power for doubly-fed asynchronous generator control is obtained primarily by wind turbine control. The control objective of the wind turbine is to obtain the maximum power from the wind energy as far as possible within the allowable range of wind turbine speed, the current and voltage limitation of the doubly-fed asynchronous generator and the power electronic converter. When the available power in the wind energy exceeds the rated power of the generator, the variable pitch control mechanism will be activated to limit the power and wind turbine speed below the rated speed. The system will use the following means to control the electrical power or torque to achieve maximum Power tracking.

The way in this paper is to obtain the reference value of the rotor speed from the maximum power tracking characteristic, and then adjust the wind turbine speed to the parameter value by closed-loop control. The rotor speed control loop is as follows: 


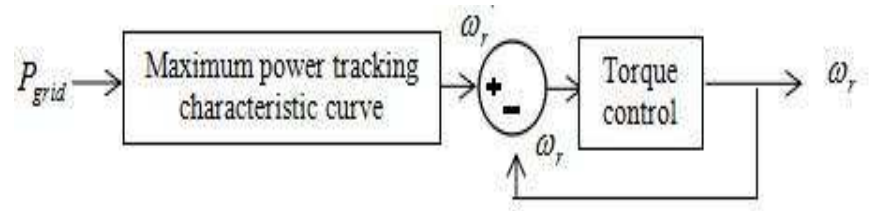

Figure 2. Active power control

The reactive power reference acquisition method includes voltage regulation at the network connection, power factor command and directive reactive power support. It is shown below:

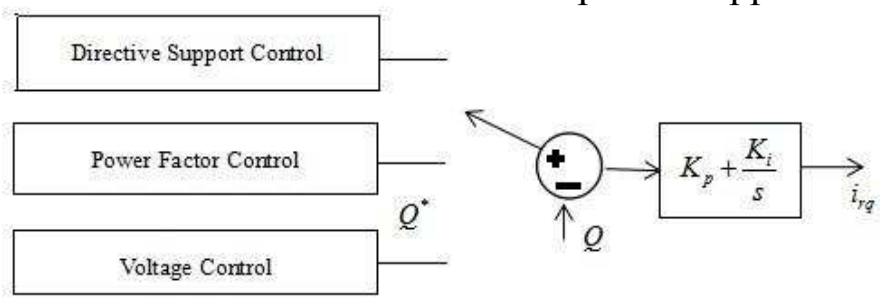

Figure 3. Reactive power control

\section{Simulation}

A wind farm usually includes a few wind turbines, and it is not necessary to separately describe each wind turbine in a wind farm if the main effect of the wind farm on the system's dynamic performance is investigated. Usually, wind farms are described as a suitable equivalent wind turbine and are interconnected with the grid at the appropriate point of interconnection.In this paper, the numerical simulation of the doubly fed generator system is carried out by using the control method described above, and the corresponding results are given. The simulation results verify the correctness of the model[9-10].

The simulation set is that the wind speed increases from $10 \mathrm{~m} / \mathrm{s}$ to $12 \mathrm{~m} / \mathrm{s}$ in $5 \mathrm{~s}$. The maximum power tracking method is used to control the active power. The reactive power control method includes voltage control and setpoint control.

Fig. $4 \mathrm{a}, 4 \mathrm{~b}$ gives the wind speed, rotor speed curve. It can be seen from the figure, the rotor speed changes with the wind speed, to ensure that the blade speed ratio for the optimal value.
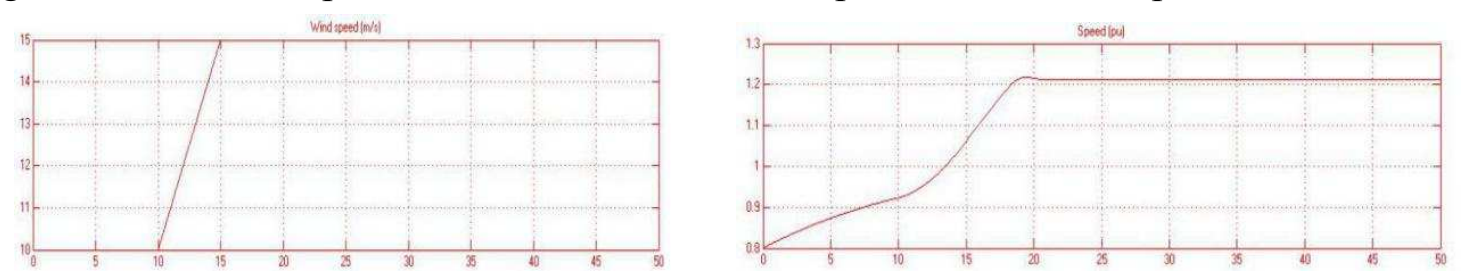

Figure 4a. Wind Speed 4b. Rotor Speed

Fig.5a,5b shows the system's active power and current.
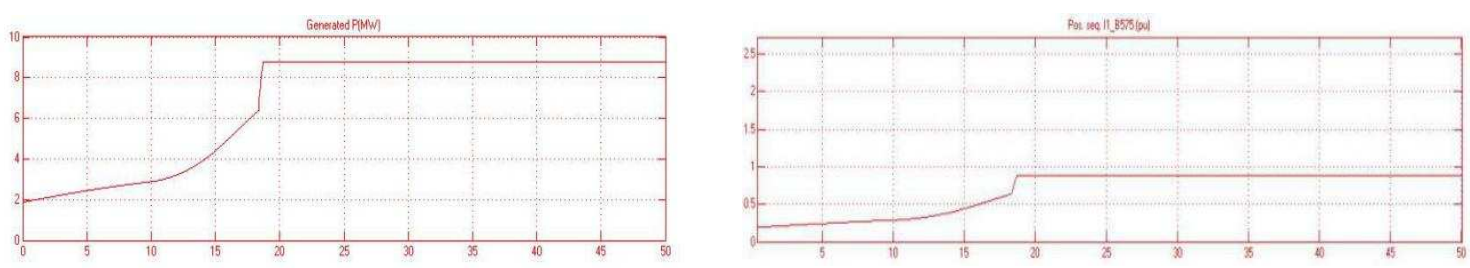

Figure 5a. Generated Active Power 5b. Generated Current 
Fig. $6 a, 6 b$ shows the reactive power generated by the system under voltage control and setpoint control.
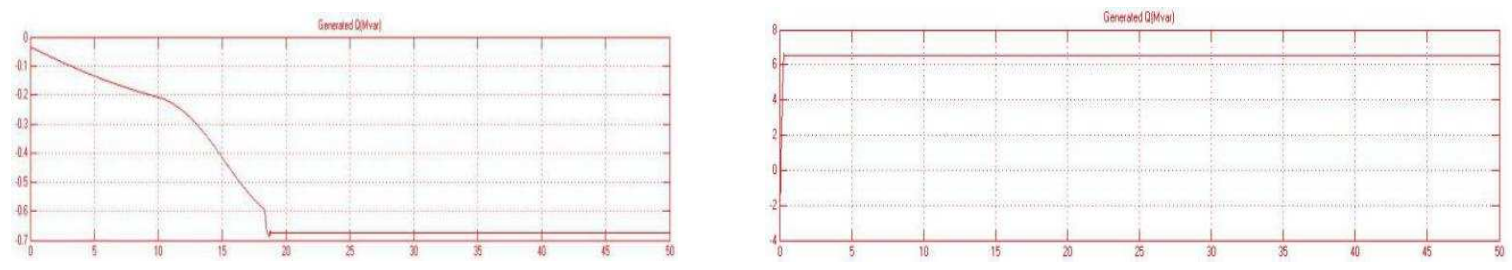

Figure 6a. Generated Positive Power under voltage control 6b. Generated Positive Power under setpoint control

\section{Conclusion}

Based on the Matlab/Simulink software,the dynamic simulation of the double-fed wind turbine is carried out. The wind speed model is used to simulate the double-fed wind turbine. The maximum wind energy capture and decoupling control is realized. The simulation results show that the double The wind turbine generator set has good running characteristics, and validates the correctness and validity of the model.Firstly, the model established by Matlab / Simulink has laid a good foundation for the further study of doubly-fed wind turbine.

\section{Reference}

[1] Vijay Vittal\&Raja Ayyanar. Grid integration and dynamic impact of wind energy.China machine press, 2014.

[2] XU Xiwang\&LI Gengyin. Study on modeling and simulation of doubly-fed induction wind turbine based on Matlab / Simulink [J].Power Grid \& Clean Energy, 2010, (11): 95-101.

[3] Eduard Muljadi\&Vahan Gevorgian.Understanding Dynamic Model Validation of Wind Turbine Generator and a Wind Power Plant.IEEE Energy Conversion Congress and Exposition.2016.

[4] N.W Milller et al.Western Wind and Solar Integration study phase 3 Frequency response and transient stability.NREL/SR-5D00-62906.2014.

[5] MA Yi-wei,et al.Study on maximum power point tracking control strategy for doubly-fed wind power generation system[J].Journal of Electrical Engineering, 2009, (04): 202-208.

[6] LUO Cheng-xian.State Status and Prospect Forecast of World Wind Power [J] .China \& Foreign Energy, 2012, (03): 24-31.

[7] Hossein Kazemi KAREGAR,Maryam KHODDAM. Effects of Wind Turbines Equipped with Doubly-fed Induction Generators on Distance Protection[J].Power Automation 2012,(08):128-131.

[8] Yun SHI,Ai LIU,Chengwu LIN. System Modeling and Simulation of a Wind Power Generation with Doubly Fed Induction Generator[A].Proceedings of 2016 6th International Conference on Mechatronics,Materials,Biotechnology and Environment(ICMMBE 2016)[C].Information and Engineering International Society,2016:5.

[9] Shenyang Wu,Daniel Kirschen. A novel transient rotor current control scheme of a doubly-fed induction generator equipped with superconducting magnetic energy storage for voltage and frequency support[J]. Chinese Physics B,2015,(07):54-65. 
[10] Zhang Wenjuan,Huang Shoudao, Chen Zhe. An analytic electromagnetic calculation method for performance evolution of doubly fed induction generators for wind turbines[J]. Journal of Central South University,2013,(10):2763-2774. 